\title{
Method for designing energy-efficient ventilation systems based on regenerative heat exchangers
}

\author{
Nikolay Monarkin ${ }^{1, *}$, Anton Sinitsyn ${ }^{1}$, Denis Karpov $^{1}$ and Timur Akhmetov ${ }^{2}$ \\ ${ }^{1}$ Vologda State University, Institute of civil engineering, 160000 Vologda Lenina str. 15, Russia \\ ${ }^{2}$ Kazan State Power Engineering University, Kazan, Russia
}

\begin{abstract}
The method of designing ventilation systems based on stationary switching regenerative heat exchangers is presented. Recommendations for selection of rational device parameters are given and substantiated. The diameter and thickness of a single channel wall of regenerative nozzle; the total diameter and length of nozzle; the time of heat accumulation or regeneration stages; the heat capacity and density of nozzle material; air flow rate are considered.
\end{abstract}

\section{Introduction}

Nowadays residential multi-apartment buildings in Russia and other countries have problems of ensuring the required air exchange of rooms due to the use of hermetically sealed plastic windows and wear of existing ventilation systems [1]. Moreover, the heat consumption for ventilation can reach $50 \%$ of the total energy consumption of a building $[2,3]$. One of the solutions to these problems is the use of compact ventilation devices called stationary switchable regenerative heat exchangers (SSRHE). These devices enable air exchange due to their paired installation in premises, and are also able to return (utilize) part of thermal energy of the indoor air to the room.

Given the relevance of SSRHE usage, a generalized approach to their design and application is needed. The works [4-7] present some recommendations regarding the installation of SSRHE and their use in certain rooms, but such recommendations are not exhaustive. Therefore, the purpose of this paper is to create a method for designing and selecting SSRHE for ventilation systems in building. The method is based on the previously published studies [8-10].

\section{Materials and methods}

SSRHE consists of a regenerative nozzle, which performs the function of a heat exchanger, and a reversible fan, enabling changing the stages of air supply and exhaust (Figure 1). In figure 1: 1 - fan; 2 - nozzle; 3 - housing; 4 - thermal insulation; 5 - outdoor enclosure; $T_{\text {in }}$ and $T_{\text {out }}$ are temperatures of internal and external air, respectively, ${ }^{\circ} \mathrm{C} ; G_{\text {acc }}$ and $G_{\text {reg }}$ are air consumptions at the stage of heat accumulation and regeneration, respectively, $\mathrm{kg} / \mathrm{h} ; D$ is the total nozzle diameter, $\mathrm{m}$. The nozzle is a solid-state cylinder penetrated by many channels of small diameter for air passage. The SSRHE operation consists of alternately switching the stages of accumulation of the internal air heat by the nozzle (air extraction mode) and heat recovery by heat transfer from the nozzle to the external passing air (inflow mode). These devices are installed in external walls. [1].

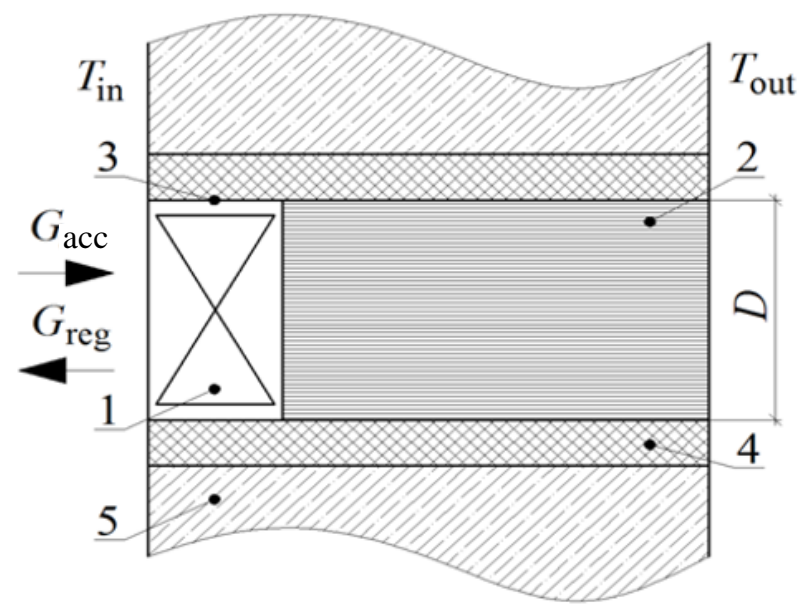

Fig. 1. Schematic diagram of SSRHE.

The purpose of designing ventilation systems based on SSRHE is to determine the nozzle parameters, the number of devices to be installed, the air flow through a separate SSRHE, and the choice of fan size.

Nozzle parameters should be selected based on rationality. The rationality of parameters was estimated by the energy efficiency coefficient of SSRHE, which is the ratio of the actual energy used by the regenerator to the maximum possible energy for use:

$$
E=\frac{\delta T}{\Delta T_{\max }},
$$

where $\Delta T_{\max }=\left(T_{\text {in }}-T_{\text {out }}\right)$ is the maximum possible cooling or heating of air in the nozzle from $T_{\text {in }}$ to $T_{\text {out }}$,

Corresponding author: nikolay-monarkin@ yandex.ru 


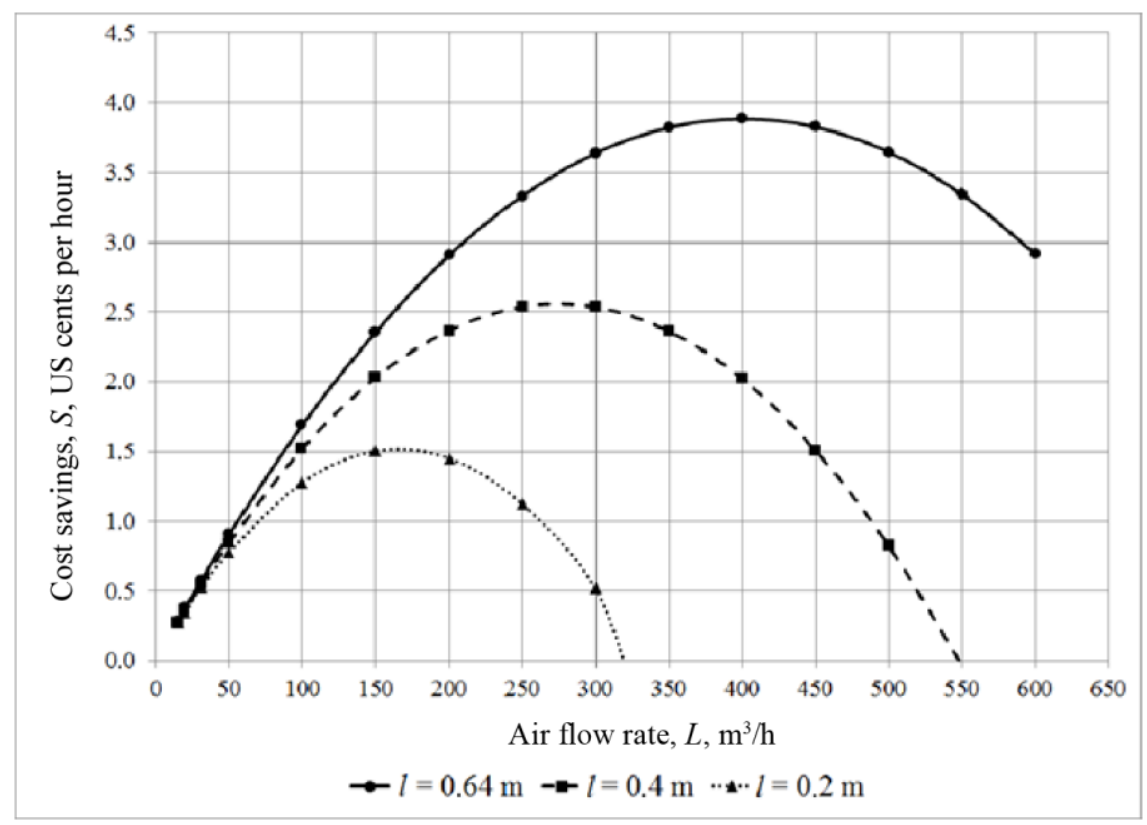

Fig. 2. Relationship between cost savings and air flow rate through SSRHE for various nozzle lengths.

${ }^{\circ} \mathrm{C} ; \delta T$ is cooling (heating) of internal air in the nozzle averaged for the accumulation (regeneration) stage, ${ }^{\circ} \mathrm{C}$, it was obtained from mathematical modelling of heat transfer between air and nozzle in a single SSRHE channel [9].

The nozzle design is considered energy efficient for $E \geq 0.9$.

The air flow rate through the SSRHE is also assessed in terms of rationality. In case of increase in air flow rate, the regenerator thermal efficiency $E$ decreases, and the aerodynamic losses in nozzle increase, but at the same time, the regenerator productivity $L\left(\mathrm{~m}^{3} / \mathrm{h}\right)$ increases. Therefore, it is possible to determine the optimal value of air flow rate as a compromise between performance and resistance. For this, the function of saving money costs $S$ (United States cents per hour) when using SSRHE, was tested on optimum [10]:

$$
S=c_{a}\left(T_{\text {in }}-T_{\text {out }}\right) C_{H}\left(-a_{1} L^{2}+E_{0} L\right)-2 a_{2} L^{2} C_{E},
$$

where $c_{\mathrm{a}}$ is the mass heat capacity of air, $\mathrm{J} /(\mathrm{kg} \cdot \mathrm{K})$;

$C_{\mathrm{H}}$ is the cost of heat energy, US cents per $\mathrm{kWh}$;

$C_{\mathrm{E}}$ is the cost of electric energy, US cents per kWh;

$a_{1}$ and $a_{2}$ are the coefficients depending on nozzle parameters;

$E_{0}$ is the initial value of coefficient $E$.

Figure 2 shows, as an example, the relationship between $S$ and air flow for various regenerative nozzle lengths. The curves were calculated for the following data: $C_{\mathrm{H}}=28.6$ US dollars per $\mathrm{kWh} ; C_{\mathrm{E}}=6.43$ US cents per $\mathrm{kWh} ; T_{\text {in }}=21^{\circ} \mathrm{C} ; T_{\text {out }}=-4^{\circ} \mathrm{C} ; d=4 \mathrm{~mm} ; \delta=0.5 \mathrm{~mm}$; $\tau_{\mathrm{acc}}=\tau_{\mathrm{reg}}=40 \mathrm{~s}$. The figure shows that the longer the SSRHE is, the higher are the savings in cash costs. Under these conditions, the optimal air flow rates are: $L=150 \mathrm{~m}^{3} / \mathrm{h}$ for $l=0.2 \mathrm{~m}$ and $S=1.50$ US cents per hour; $L=250 \mathrm{~m}^{3} / \mathrm{h}$ for $l=0.4 \mathrm{~m}$ and $S=2.54$ US cents per hour; $L=400 \mathrm{~m}^{3} / \mathrm{h}$ for $l=0.64 \mathrm{~m}$ and $S=3.89$ US cents per hour.
The upper curve of Fig. 2 is limited by air flow rate of $600 \mathrm{~m}^{3} / \mathrm{h}$, since if this value is exceeded at $d=4 \mathrm{~mm}$, the flow mode will change from laminar to turbulent, and the used calculation method will be incorrect. The tendency of the lower curves to zero along the ordinate axis indicates that there will be no savings when exceeding the shown air flow rates.

\section{Results and discussion}

Further the rational parameters of the SSRHE nozzle will be discussed.

Diameter of a unit nozzle channel $(d)$. This parameter should be selected judging from a compromise between pressure loss and energy efficiency $E$. It was determined that the smaller diameter of channel provides larger cost savings. However, if the size of channels is too small, they can be covered and clogged with dust and ice during moisture condensation. Therefore, it is recommended to take the channel diameter in the following range: $d=0.003-0.005 \mathrm{~m}$.

Wall thickness of a single channel $\delta$. Wall thickness between the nozzle channels should not be too small. With a decrease in wall thickness, the number of channels increases and the thermal efficiency increases. However, a decrease in wall thickness leads to a decrease in the nozzle mass, which will adversely affect its heat-storage ability and require less cycle time. Also this can result in difficulties during nozzle fabrication and in a decrease in its strength. It is recommended to take the wall thickness of the nozzle channel in the following range: $\delta=0.4-0.6 \mathrm{~mm}$.

Stage time $\left(\tau_{\text {acc }}, \tau_{\text {reg }}\right)$. It was determined that a decrease in time of heat accumulation/regeneration stage leads to an increase in SSRHE efficiency. However, the time cannot be too small, since during the regenerator operation the high-quality assimilation of the supply air 


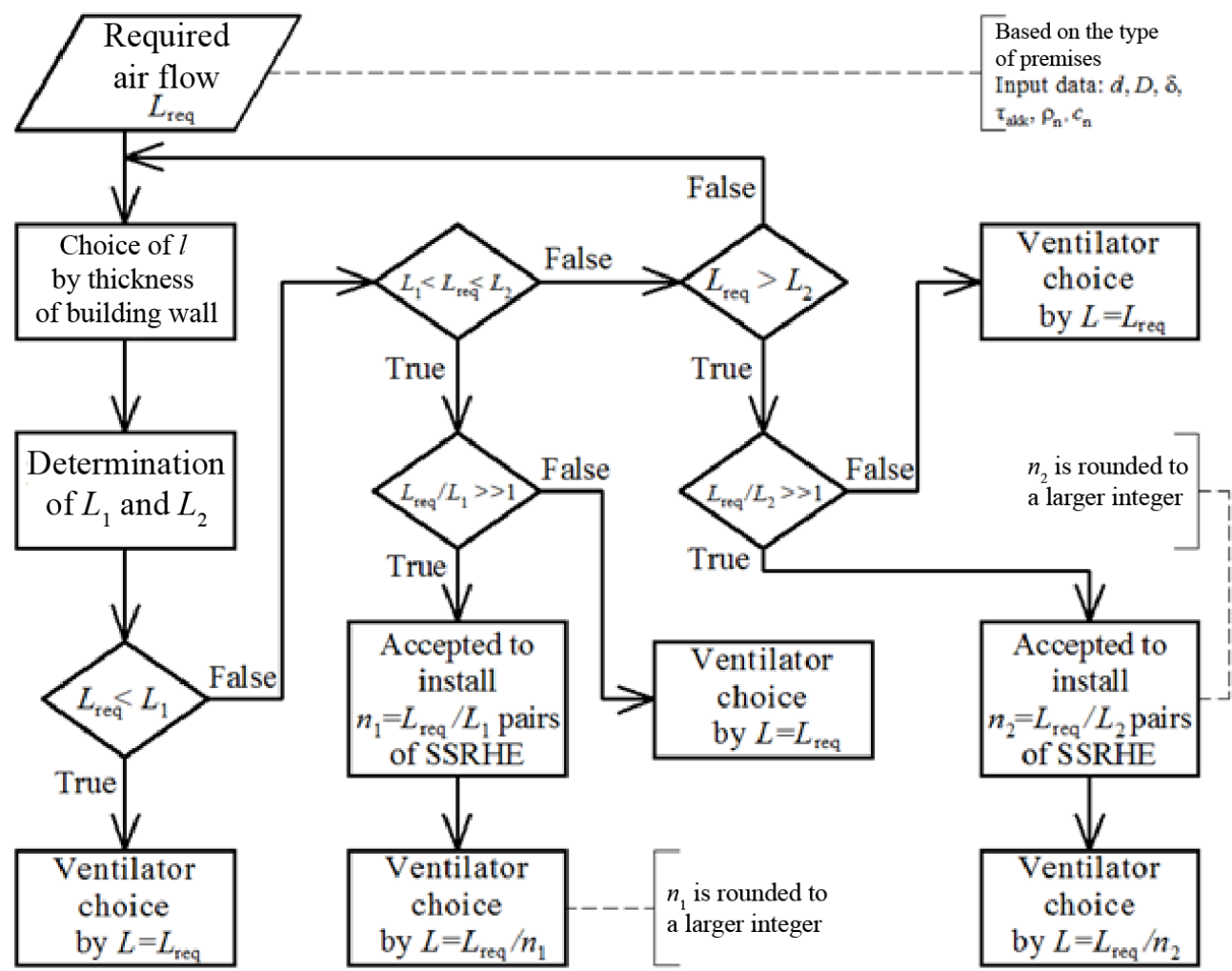

Fig. 3. Flowchart of the algorithm of the engineering method for designing a ventilation system based on SSRHE.

must be ensured, which requires sufficient time to form a stable supply jet. That is, during one stage of SSRHE operation, a sufficient amount of external air must be supplied to allow air exchange in the entire volume of room, and not just around the device itself. Therefore, it is recommended to take $\tau_{\text {acc }}=\tau_{\text {reg }}=30-50 \mathrm{~s}$.

Density $\left(\rho_{n}\right)$ and heat capacity of the nozzle material $\left(c_{n}\right)$. These thermophysical parameters of nozzle do not significantly affect the change in SSRHE efficiency. The following density ranges are recommended: $\rho_{\mathrm{n}}=1400$ $2000 \mathrm{~kg} / \mathrm{m}^{3}$. The recommended heat capacity of nozzle material is in the range $c_{\mathrm{n}}=2000-3000 \mathrm{~J} / \mathrm{kg} \cdot \mathrm{K}$. Among the existing materials, polymers, including various plastics, are the most suitable for the indicated ranges. So, structurally complex products can be constructed from them. Ceramic nozzles are also used in the existing SSRHEs, but their heat capacity hardly exceeds 1000 $\mathrm{J} / \mathrm{kg} \cdot \mathrm{K}$.

Total nozzle diameter $(D)$. The total nozzle diameter affects the total heat transfer area, via the number of channels for air passage. The diameter of SSRHE housing as well as nozzle diameter is determined by the permissible size of holes in the outer walls of building, based on the strength conditions and the building appearance. For certain hole sizes, a special project for their implementation, as well as measures to strengthen the wall structure, may be required. In some regions of Russia, the maximum dimensions of holes in the external walls are stipulated, for which it is not necessary to develop a project for the construction of an architectural opening. Based on review of regulatory documents, the recommend allowable hole size is up to $0.2 \mathrm{~m}$.

Based on the foregoing, the following algorithm of method for designing energy-efficient ventilation systems based on SSRHE is proposed (Figure 3):

1. The required air flow rate $L_{\mathrm{req}},\left(\mathrm{m}^{3} / \mathrm{h}\right)$ for ventilation is determined according to the norms based on the type of premises, or according to the calculation based on the released hazards.

It is known that the simplest way to determine the required air exchange is to use standard multiplicity. In this case, the air exchange rate can be given either in the form of the number of room volumes, or in the form of a norm per unit area, per unit volume, per unit of equipment, per person. When determining the required air exchange by calculation, it is necessary to use the methods described in the standards and academic literature.

2. The length of regenerator nozzle $l(\mathrm{~m})$ is selected according to the thickness of the building outer wall.

The length of the regenerative nozzle directly depends on the entire SSRHE length, which takes into account the fan length. The total SSRHE length depends on the thickness of the building outer wall where the device is mounted. The wall thickness depends on the material used, as well as on the climatic parameters of the construction area. According to the existing wall thicknesses of buildings made of various materials, the nozzle length can vary between 0.2-0.64 m. However, the existing SSRHE models include that installed outside the wall structure, and the device is connected with the 


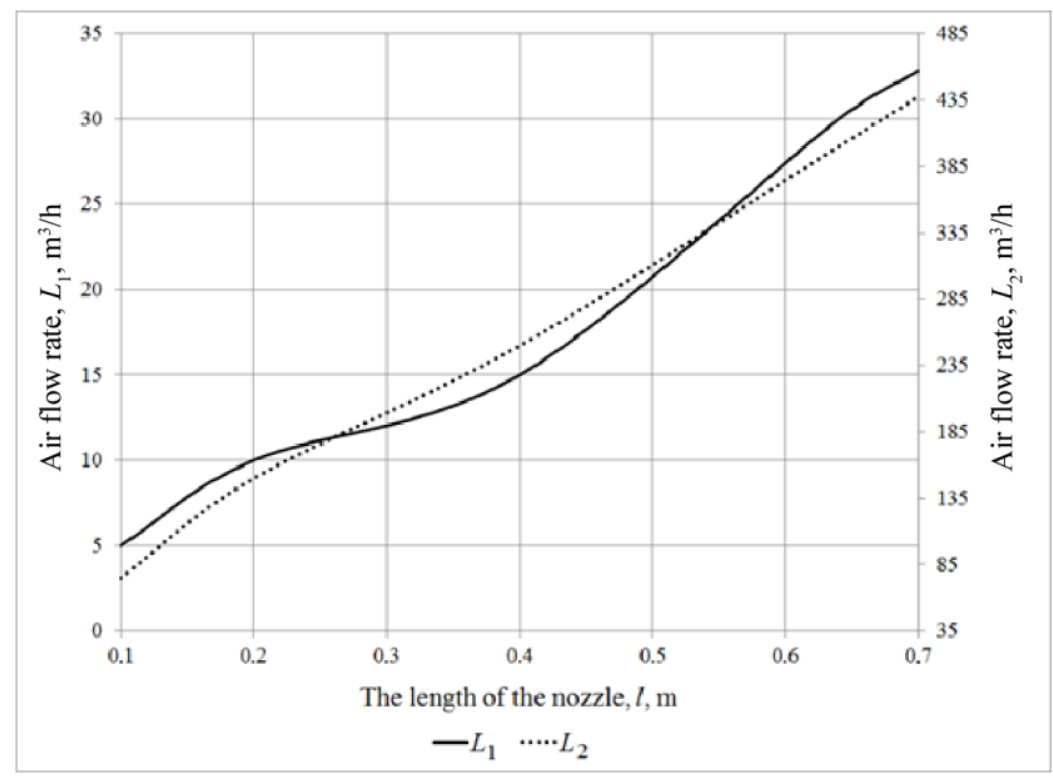

Fig. 4. Relationship between the flow rates $L_{1}$ and $L_{2}$ and the length of the nozzle.

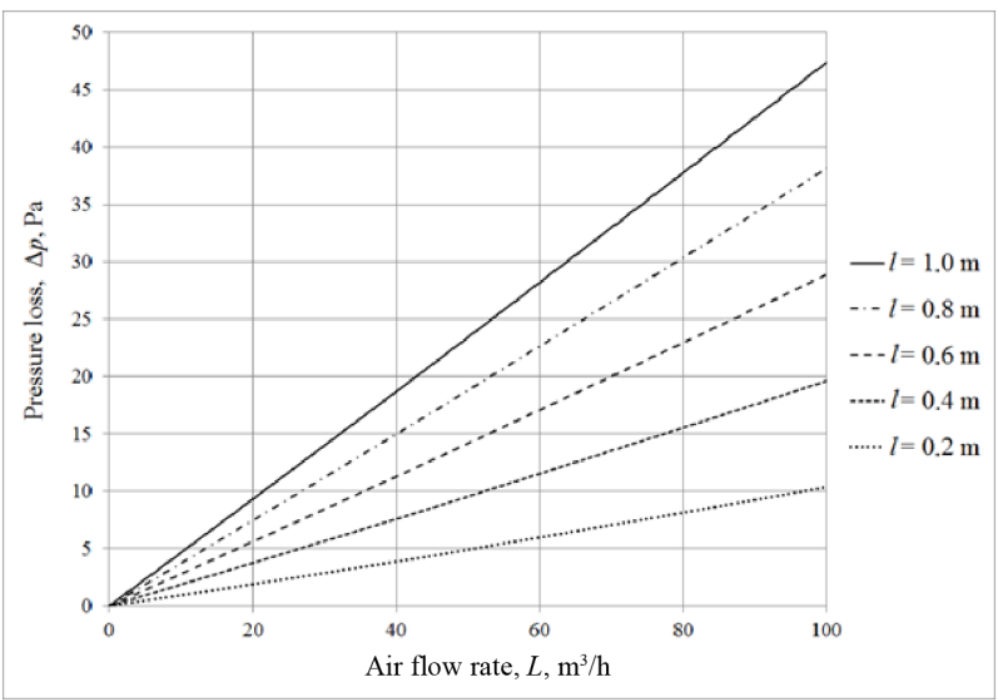

Fig. 5. Relationship between pressure loss and air flow rate and the length of the nozzle.

external environment through the air duct. In such cases, the diameter of duct passing through the outer enclosure can be reduced, and the wall thickness does not affect the nozzle length.

3. Using the calculated nozzle length, the following air flow rates $\left(\mathrm{m}^{3} / \mathrm{h}\right)$ are determined: $L_{1}$ is the flow rate, for which the thermal efficiency of the regenerator is $E=0.9 ; L_{2}$ is the flow rate, for which the cost savings $S$ for heat and electric energy are maximized. Obviously, $\mathrm{L}_{2}>\mathrm{L}_{1}$.

4. $L_{\text {req }}$ is compared with $L_{1}$ and $L_{2}$ with three possible results: 1) $L_{\text {req }}<L_{1}$; 2) $L_{1}<L_{\text {req }}<L_{2}$; 3) $L_{\text {req }}>L_{2}$.

5. If $L_{\text {req }}<L_{1}$, it is advisable to install a pair of regenerators to work in antiphase. From flow $L=L_{\text {req }}$ pressure losses in regenerator $\Delta p$ are determined. Fan is selected according to $L$ and $\Delta p$.
6. If $L_{1}<L_{\mathrm{req}}<L_{2}$, then the ratio $n_{1}=\frac{L_{\mathrm{req}}}{L_{1}}$ is calculated and rounded to a larger integer. Two solutions are possible here:

a) when $n_{1}>>1$ it is recommended to install $n_{1}$ pairs of SSRHE with air flow through each $L=\frac{L_{\text {req }}}{n_{1}}$, by which pressure losses are determined, and a fan is selected;

b) when $n_{1}$ slightly exceeds 1 it is recommended to install one pair of SSRHE with air flow through each $L=L_{\text {req }}$, by which pressure losses are determined, and a fan is selected.

7. If $L_{\text {req }}>L_{2}$, the ratio $n_{2}=\frac{L_{\text {reg }}}{L_{2}}$ is calculated and rounded to a larger integer. Two solutions are also possible here:

a) when $n_{2}>>1$ it is recommended to install $n_{2}$ pairs of SSRHE with air flow through each $L=\frac{L_{\mathrm{req}}}{n_{2}}$, by 
which pressure losses are determined, and a fan is selected;

b) when $n_{1}$ slightly exceeds 1 it is recommended to install one pair of SSRHE with air flow through each $L=L_{\text {req }}$, by which pressure losses are determined, and a fan is selected.

To determine the flow rates $L_{1}$ and $L_{2}$ as a function of nozzle length, the nomogram was built, shown in Figure 4. To determine the pressure loss in nozzle $\Delta p$ from the air flow rate and the nozzle length, a nomogram was built, shown in Figure 5. Nomograms are built for the source data: $d=4 \mathrm{~mm}, \tau_{\mathrm{acc}}=40 \mathrm{~s}, D=200 \mathrm{~mm}, \delta=0.5 \mathrm{~mm}$.

It should be noted that this method does not take into account the influence of SSRHE on the moisture conditions of room. Moreover, if there is no significant release of moisture in the room, then upon steady-state air exchange, the moisture content of the internal air will be equal to that of external air. In this case, in the cold season, there may be a need for humidification of air with special devices, which is a separate issue for study.

Also, the method does not address the issue of compliance with the permissible noise level during the SSRHE operation. But the use of low-power (lowperformance) fans in SSRHE design resolves this question.

\section{Conclusions}

Based on the performed studies a method was developed to select the SSRHE parameters, the number of installed devices, the air flow through a separate SSRHE and size fans through the required room air exchange. An appropriate algorithm has been compiled, which significantly reduces the time, which design-engineer spends for the parameters selection. This algorithm has a simplified scheme, and doesn't require solving a complex system of interconnected heat transfer equations between the air and the regenerative nozzle.

\section{References}

[1] A.A. Sinitsyn, N.N. Monarkin, T.V. Rogulin, Automation and energy saving of machine-building and metallurgical industries, technology and reliability of machines, instruments and equipment: materials of the 9th International Scientific and Technical Conference, 202-205 (2014)

[2] R.K. Calay, W.C. Wang, The 12th International Conference on Air Distribution in Rooms (2011)

[3] I.A. Sultanguzin, E.V. Zhigulina, Y.V. Yavorovsky, I.D. Kalyakin, A.V. Govorin, A.V. Fedyukhin, A.A. Krolin, S.V. Guzhov, O. Derevianko, L. Mukhametova, Development strategy of the energy supply system for MPEI campus blocks based on green building, IOP Conference Series: Earth and Environmental Science 288, 1, 012071 (2019).

[4] V.A. Vasiliev, A.I. Gavrilov, K.K. Kamenetsky, E.V. Sobol, Journal of the International Academy of Refrigeration, 1 (2010).
[5] A.A. Zakharov, M.I. Nizovtsev, Scientific Bulletin of NSTU, 1, 54 (2014).

[6] M.R. Nasr, M. Fauchoux, R.W. Besant, C.J. Simonson, Renewable and Sustainable Energy Reviews 30 (2014).

[7] D.G. Moghaddam, A. Oghabi, G. Ge, R.W. Besant, C.J. Simonson, Applied Thermal Engineering 61 (2013).

[8] N. Monarkin, S. Lukin, Yu.M. Anurov, B.A. Tihomirov, G.A. Agasiants, S.M. Galileev, T.R. Akhmetov, IOP Conf. Series: Earth and Environmental Science 337 (2019).

[9] N.N. Monarkin, S.V. Lukin, A.A. Kochkin, Volga Scientific Journal 3, 47 (2018).

[10] N.N. Monarkin, S.V. Lukin, A.A. Kochkin, BST: Bulleten' stroitel'noy tehniki 6, 1018 (2019). 